\section{Brightness and direction as cues for spontaneous alternation behavior ${ }^{1}$}

JAMES L. PATE and JUDY DeLOACHE, Georgia State College, Atlanta, Ga 30303

In a study designed to test the relative effectiveness of spatial direction and brightness cues for spontaneous alternation, 29 rats were run in a grey T-maze with black and white inserts in the goal arms. Odor-trail cues were eliminated by changing the paper flooring of the maze between trials and between Ss. In Part A, the $S$ s received two daily trials, with the inserts switched between Trials 1 and 2 to contrast direction and brightness cues-to alternate spatial direction, a rat had to repeat brightmess. Insignificant alternation occurred with this procedure. In Part B, when the Ss were forced four times to the same direction and stimulus insert and then were given a free trial with the inserts switched to contrast cues, significant alternation of spatial direction was observed. In Part $C$, when $S$ s received four forced trials to opposite arms but to the same stimulus insert, brightness was alternated significantly. The alternation rates in the three parts of the experiment were interpreted as evidence that brightness is an important cue for spontaneous alternation.

A number of experiments on spontaneous alternation behavior have been concerned primarily with the determination of the cues for alternation. While several investigators, including Glanzer (1953), Walker, Dember, Earl, \& Karoly (1955), and O'Connell (1964), claimed to have found alternation of visual stimuli, Douglas (1966) has concluded that only odor trail and spatial direction are effective as cues for alternation. This assertion seems doubtful in view of the fact that brightness has been shown to be a critical factor in experiments involving stimulus change (Dember, 1956; Dember \& Millbrook, 1956; Kivy, Earl, \& Walker, 1956; O'Connell, 1964) and exploration (Montgomery, 1953), two phenomena that are closely related to spontaneous alternation behavior. Accordingly, the present experiment attempted to assess the relative contribution of visual and spatial-direction cues for alternation with odor-trail cues eliminated.

\section{SUBJECTS}

The Ss were 36 gentled, experimentally naive male albino rats of the Sprague-Dawley strain, approximately 100-130 days old at the beginning of the experiment. Seven Ss were eliminated for failure to meet running criteria specified below, leaving 29 Ss for the experimental analysis. The rats were individually housed and were maintained on approximately two laboratory pellets per day and $22 \mathrm{~h}$ of water deprivation. They were never rewarded in the experimental apparatus.

\section{APPARATUS}

The apparatus consisted of a wooden $T$-maze and detention box, both covered with hardware cloth and painted flat grey. The detention box was a 12 -in. cube, and the T-maze had the following dimensions: The arms were $18 \times 4 \times 6$ in. high; the start stem was $24 \times 4 \times 6$ in. high. The first 6 in. of the start stem were separated from the rest of the stem by a wooden guillotine door to form a startbox. Wooden guillotine doors were located at the entrances to the goal arms. Black and white inserts were placed on the walls of the arms, and heavy brown paper served as the maze floor.

\section{GENERAL PROCEDURE}

Throughout all parts of the experiment, $S$ was carried to the experimental room in his home cage and was placed in the startbox. After approximately $5 \mathrm{sec}$, the startbox door was opened. When the rat's whole body was in one of the alleys, the goal arm door was lowered, and the animal was detained in the chosen arm approximately $15 \mathrm{sec}$. The $S$ was then removed from the arm and placed in the detention box for approximately $45 \mathrm{sec}$ while the maze was prepared for the next trial. Subsequent trials were conducted in the same manner as was the first, with the paper flooring changed before the test trial to control for odor cues. Following the test trial, $S$ was returned to the animal room. The paper flooring was changed between Ss.

If $S$ failed to leave the startbox in $3 \mathrm{~min}$, it was pushed out; if it failed to enter an alley within $5 \mathrm{~min}$ after leaving the startbox, it was removed from the maze, and "no choice" was recorded. Any animal that failed to enter an arm in the specified time on 3 days was eliminated from the experiment. Whenever an $\mathbf{S}$ was handled, care was taken to turn the animal as little as possible to avoid disturbing its orientation.

\section{Part A}

Part A consisted of two trials on Days 1 through 10 . The stimulus inserts were switched between Trials 1 and 2 so that if the black insert had been in the left arm on Trial 1, it was in the right on the test trial. With this procedure, an $S$ could alternate spatial direction or brightness but not both. The position of the black insert on Trial 1 for each of the 10 days was assigned randomly. One-half of the animals were given this sequence, and one-half of the Ss were given the same sequence with white replacing black.

\section{Part B}

On Day 13, Part B was begun. On each of the next 5 days, each $S$ was forced four times to the same stimulus in the same arm by having only the door to the forced arm raised. Then the inserts were switched, and $S$ received a free-choice trial. For example, $S$ might be forced four times to the black insert on the left and then be given a free-choice trial with black on the right. As in Part A, the rat had to repeat the previous brightness cue in order to alternate spatial direction. On each day, one-half of the Ss were forced to the black stimulus and one-half to the white. One-half of the Ss in each of these two groups were forced left and one-half right.

\section{Part C}

On Days 20 through 24, the rats were run in Part C. On each day, each $\mathrm{S}$ received four forced trials to the same stimulus insert but to alternating directions. For example, $S$ might be forced to black on the left, then to black right, black left, and black right. The inserts were then switched, and $S$ received a free-choice trial. Thus, to alternate the spatial direction of the last forced trial, $S$ had to repeat the brightness cue experienced on the four previous trials. The four stimulus conditions employed for the first trial were balanced as in Part B.

\section{RESULTS}

For this study, alternation was defined as alternation of spatial direction (and, hence, repetition of maze brightness). In Part A, when inserts were switched between Trials 1 and 2 to contrast direction and brightness cues, the mean alternation rate was $52.85 \%$. This did not differ from the a priori chance level of $50 \%$ and was considerably lower than the $70 \%-80 \%$ alternation typically observed when all cues except odor trail were available and stationary. The procedure in Part B-four forced trials to the same place and brightness with the inserts then switched to contrast spatial and brightness cues-resulted in $62.75 \%$ alternation. Using the normal curve approximation to the binomial, the alternation in Part $B$ was found to be significantly higher than the $50 \%$ chance level $(z=3.07, p<.001)$. In Part $\mathrm{C}$, when $\mathrm{S}$ was forced to opposite arms but to the same brightness with the cues again contrasted on the test trial, only $31.03 \%$ alternation of spatial direction occurred. (This figure is equivalent to $68.97 \%$ brightness alternation.) This alternation rate was significantly lower 
than chance $(z=4.57, p<.001)$. The per cent alternation for each $S$ in each part of the experiment was subjected to the arc sine transformation, and an analysis of variance indicated a significant difference between the alternation rates in the three parts of the experiment $(F=20.51$, $\mathrm{df}=2 / 54, \mathrm{p}<.001)$.

Response biases were analyzed for Part A, but not for Parts B and C because of the forcing procedure, by comparing the number of right vs left turns and the number of black vs white stimuli chosen on Trial 1. There was no evidence of a turn bias, but a significant preference $(60 \%)$ for the black stimulus was found $(z=3.35$, $\mathrm{p}<.001)$. The Part $\mathrm{A}$ alternation rate was modified by applying the correction for bias suggested by Dember \& Fowler (1958); only a slight change resulted, and the alternation rate still did not differ from chance level.

\section{DISCUSSION}

The alternation rates reported here indicate that, contrary to Douglas's (1966) assertion, visual stimuli do function as cues for alternation behavior. When inserts were switched between the first and second trials to contrast brightness and direction cues, the rate of alternation (52.85\%) did not differ from chance. The fact that this procedure reduced alternation to chance, rather than merely decreasing the rate of direction alternation below that typically observed, suggests that brightness and direction are equally important as cues for alternation.

In Part B, spatial direction was alternated significantly $(62.75 \%)$, even though the two cues were again contrasted on the test trial. In this part, the procedure involved four forced trials to the same direction and stimulus insert and a test trial with the inserts switched. Assuming there is a tendency to alternate brightness as well as a tendency to alternate direction (as Part A indicates), then each forced trial should have increased both tendencies as $S$ repeatedly experienced the same stimulus and direction. If the tendencies increased at the same rate, then they should have been equal on the test trial, and the alternation rate would not differ from chance. This was not the case, since significant alternation of spatial direction did occur. The inference can be made, therefore, on the basis of Parts A and B, that, initially, the tendencies to alternate direction and brightness were approximately equal, but that the direction-alternation tendency increased at a greater rate with repeated experience with the same alternatives than did the stimulus-alternation tendency. It appears, therefore, that, in the present experiment, the four forced trials caused the direction-altemation tendency to be strengthened sufficiently to overcome the contrasted brightness-alternation tendency and to produce significant alternation.

The significantly lower-than-chance alternation (31.03\%) of spatial direction obtained in Part C, when Ss were forced to the same stimulus insert in opposite arms, may also be interpreted as significantly higher-than-chance $(68.97 \%)$ brightness alternation. This finding offers further evidence that maze brightness does function as an important cue for alternation. The repeated forcing to one brightness caused an increment in the tendency to alternate that cue, while the alternation tendency for direction existed relative only to the last forced trial. On the test trial, there was thus a stronger tendency to go to a different brightness than to run in a different direction.

\section{REFERENCES}

DEMBER, W. N. Resporse by the rat to environmental change. Journal of Comparative $\&$ Physiological Psychology, 1956, 49, 93-95.

DEMBER, W. N., \& FOWLER, H. Spontaneous alternation behavior. Psychological Bulletin, $1958,55,412-428$.

DEMber, w. N., \& MILlbrooK, B. A. Free choice by the rat of the greater of two brightness changes. Psychological Reports, 1956, 2, 465-467.

DOUGLAS, R. I. Cues for spontaneous alternation. Journal of Comparative \& Physiological Psychology, 1966, 62, 171-183.

GLANZER, M. The role of stimulus satiation in spontaneous alternation. Joumal of Experimental Psychology, 1953, 45, 387-393.

KIVY, P. N., EARL, R. W., \& WALKER, E. L. Stimulus context and satiation. Journal of Comparative \& Physiological Psychology, $1956,49,90-92$.

MONTGOMERY, K. C. Exploratory behavior as a function of "similarity" of stimulus situations. Journal of Comparative \& Physiological Psychology, 1953, 46, 129-133. O'CONNELL, R, H. Comparison of alternation and response to stimulus change. Journal of Comparative \& Physiological Psychology, $1964,57,362-366$.

WALKER, E. L., DEMBER, W. N., EARL, R. W., \& KAROLY, A. J. Choice altemation: I. Stimulus vs. place vs. response. Journal of Comparative \& Physiological Psychology, $1955,48,19-23$.

\section{NOTE}

1. This paper was presented at the meeting of the Southeastern Psychological Association, New Orleans, February 1969. The paper is based on the second author's Honor's Thesis submitted in partial fulfillment of the requirements for the $\mathbf{A B}$ degree.

\section{ERRATA}

McCAIN, GARVIN. Different levels of performance with equivalent weights of teward. Psychonomic Science, 1969, 14, (1), 2-3.-On page 2, 2nd column, line 20 should read ". . trials on Days 1 and 2."

SQUIER, LESLIE, H. Reversal learning improvement in the fish Astronotus ocellatus (Oscar). Psychonomic Science, 1969, 14 (3), 143-144.-The figure captions are reversed.

REBERG, D., and BLACK, A. H. Compound testing of individually conditioned stimuli as an index of excitatory and inhibitory properties. Psychonomic Science, 1969,17 (1), 30-31.-The figure did not reproduce legibly. We have therefore reproduced it for you again.

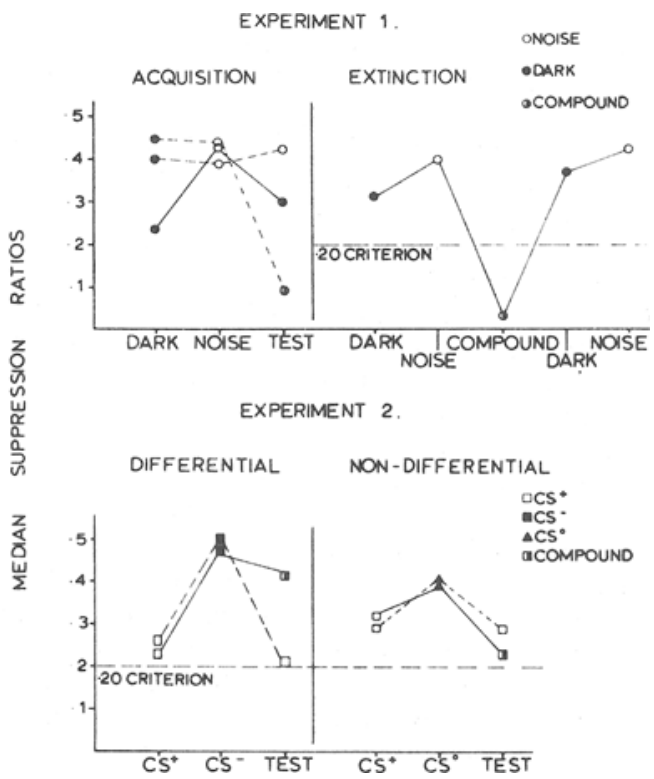

